This item was submitted to Loughborough's Research Repository by the author.

Items in Figshare are protected by copyright, with all rights reserved, unless otherwise indicated.

\title{
Droplet-based microfluidic method for robust preparation of gold nanoparticles in axisymmetric flow focusing device
}

PLEASE CITE THE PUBLISHED VERSION

https://doi.org/10.1016/j.ces.2018.10.010

PUBLISHER

(C) Elsevier

VERSION

AM (Accepted Manuscript)

\section{PUBLISHER STATEMENT}

This paper was accepted for publication in the journal Chemical Engineering Science and the definitive published version is available at https://doi.org/10.1016/j.ces.2018.10.010

\section{LICENCE}

CC BY-NC-ND 4.0

\section{REPOSITORY RECORD}

Bandulasena, Monalie, Goran Vladisavljevic, and Brahim Benyahia. 2018. "Droplet-based Microfluidic Method for Robust Preparation of Gold Nanoparticles in Axisymmetric Flow Focusing Device". figshare. https://hdl.handle.net/2134/35324. 


\title{
Droplet-based microfluidic method for robust preparation of gold nanoparticles in axisymmetric flow focusing device
}

\author{
Monalie V. Bandulasena, ${ }^{\mathrm{a}}$ Goran T. Vladisavljević, ${ }^{\mathrm{a},{ }^{*}}$ Brahim Benyahia, ${ }^{\mathrm{a},}$ \\ a'Department of Chemical Engineering University, Loughborough University, Loughborough, \\ LE11 3TU, United Kingdom
}

*Corresponding author. Fax: +44 1509223923. E-mail address: g.vladisavljevic@lboro.ac.uk (Goran T. Vladisavljević) and B.Benyahia@lboro.ac.uk (Brahim Benyahia)

\begin{abstract}
A novel microfluidic mixing strategy was developed and used to prepare polyvinylpyrrolidone (PVP) capped gold nanoparticles (AuNPs). In this process, $1 \mathrm{mM}$ tetrachloroauric acid $\left(\mathrm{HAuCl}_{4}\right)$ stream containing $1 \%(\mathrm{w} / \mathrm{v})$ PVP was injected through the inner capillary tube and mixed with $20 \mathrm{mM}$ L-ascorbic acid solution delivered co-currently through the outer coaxial capillary. The reaction mixture was hydrodynamically flow focused by the environmentally friendly oil Miglyol 840 delivered from the opposite side of the outer capillary, which resulted in the generation of reaction droplets in a tapered collection tube. The reactants were rapidly mixed within droplets by internal circulating flows induced by hydrodynamic interactions of fluids inside the droplets with the carrier oil. The size of the prepared AuNPs was measured by both dynamic light scattering and transmission electron microscopy and was found to decrease with decreasing the droplet size and increasing the difference in velocity between the two reactant streams, which improved mixing efficiency within droplets. The smallest nanoparticles were obtained when the outlet section of the injection tube was positioned at the entry section of the collection tube due to the highest shear at the liquid interface. The carrier oil formed a hydrophobic barrier between the droplets and the reactor walls preventing deposition of the synthesised particles. As a result, the size of the AuNPs was smaller than in the co-flow mixer operated with two continuous reactant streams.
\end{abstract}

Keywords: reaction droplets, gold nanoparticles, glass capillaries, continuous production, droplet-based micromixer, droplet microfluidics 


\section{Introduction}

Gold nanoparticles (AuNPs) were used as a therapeutic agent and aesthetic red colourant to decorate ornamental objects from as early as $4^{\text {th }}$ century AD (Horikoshi and Serpone, 2013). Due to simple and green routes for room temperature synthesis, biocompatibility, versatile surface chemistry, and intriguing size dependant optical properties such as surface plasmon resonance, surface plasmon absorption and scattering, AuNPs are promising nanomaterials for drug and gene delivery (Pissuwan et al., 2011), bio-imaging (Zhao et al., 2016), coatings and paints (Iwakoshi et al., 2005), bio-sensing (Raj et al., 2015), digital data storage (Kim et al., 2012; Lee, 2010), and flexible electronics (Huang et al., 2003).

Bulk mixing a suitable gold salt precursor with a reducing agent in a batch reactor is the most common synthesis method of AuNPs but suffers from a poor control over mixing conditions. Inhomogeneous mixing conditions result in large batch-to-batch variations in particle size and large particle size dispersity, which usually means that additional separation step is necessary to achieve a narrow particle size distribution. Compared to traditional batch reactors with bulk mixing, microfluidic reactors offer superior control over mixing conditions at the microscale level, continuous operation, and direct optical access to the process (Phapal and Sunthar, 2013; Tice et al., 2003; Vladisavljević et al., 2014). They allow to introduce and manipulate multiple fluid streams with unprecedented precision and screen many different operating conditions, formulations and flow patterns using very small amounts of reagents.

Continuous production of AuNPs in a two-phase microfluidic device composed of silicon wafer and wet-etched Pyrex glass, anodically bonded to each other, was reported by Wagner et al. (2004) and Wagner and Kohler (2005). Significant fouling of the micro-channels was observed due to deposition of NPs onto the reactor walls. Fouling can be minimised by $\mathrm{pH}$ control or surface modification of the reactor walls with hydrophobic silanes. AuNPs produced using ascorbic acid as a reductant were prone to deposition at $\mathrm{pH} 3$, because less than $5 \%$ of ascorbic acid molecules are dissociated at such low $\mathrm{pH}$ value. Undissociated acid molecules adsorbed onto particle surfaces cannot provide repulsion between AuNPs needed to overcome attractive van der Waals forces (Bandulasena et al., 2017). At $\mathrm{pH} \approx 10$, AuNPs were stable against aggregation and deposition in glass capillaries due to strongly charged $\mathrm{AsC}^{2-}$ anions adsorbed onto particle surfaces and electrostatic repulsion between negatively charged NPs and deprotonated silanol groups $\left(-S i-O^{-}\right)$on glass surface (Rahman and Rebrov, 2014). On the 
other hand, under alkaline conditions, the rate of particle nucleation is very high, which can lead to premature particle formation and fouling of the injection channel.

Another problems encountered with single-phase microfluidic reactors are local inertial effects due to non-linear geometry of the inlet channels, which cause significant convective flux of NPs in radial direction towards the channel walls. In addition, local vortices may develop near the injection point, which can increase the residence time of NPs and promote their growth and aggregation (Othman et al., 2015).

To overcome/mitigate the above limitations related to two-phase microfluidic mixers, a third immiscible phase can be supplied between the reaction mixture and the reactor walls (Duraiswamy and Khan, 2009). This third fluid facilitates the generation of monodisperse reaction droplets, each representing an individual reaction vessel with identical conditions, which is isolated from channel walls and all other droplets (deMello, 2006). In some studies, gas bubbles were introduced between neighbouring reagent droplets to prevent fouling of the injection channel (Duraiswamy and Khan, 2010) or to enable precise injection of subsequent portions of precursors in the multistep synthesis (Kaminski and Garstecki, 2017).

Compared to micro-reactors with continuous fluid streams, droplet-based microfluidic reactors offer reduced fouling, as the reaction mixture is completely isolated from the channel walls (Bannock et al., 2014), narrow residence time distribution (Marre and Jensen, 2010), and improved mixing due to small dimensions of droplets and internal recirculating flows due to shearing interactions of fluids inside droplets with the carrier fluid or the channel walls (Stone and Stone, 2005; Tice et al., 2003). Droplet-based microfluidic reactors are suitable for highthroughput screening, since droplets can be generated at rates exceeding $1 \mathrm{kHz}$ (Casadevall $\mathrm{i}$ Solvas et al., 2010) and they travel at constant speed along the channel, which make them convenient for data acquisition for chemical reaction kinetics (Sarrazin et al., 2007). Mixing two streams within droplets without bringing reagents into contact prior to mixing can be achieved by droplet coalescence (Nightingale et al., 2014), direct injection of a continuous fluid stream into individual droplets (Zheng and Ismagilov, 2005) or injecting two or more continuous reagent streams through a $\mathrm{T}$ junction with converging side channels into the carrier fluid (Shestopalov et al., 2004; Song et al., 2008; Zhao et al., 2012). A potential problem with mixing via $\mathrm{T}$ junction with multiple inlets is that the carrier fluid does not provide sufficient shear, which may lead to relatively large droplets and potentially inefficient mixing. 
In this study, AuNPs were synthesised for the first time by mixing two reagent streams within droplets through combination of co-flow and counter-current flow focusing in a three-phase glass capillary device. In a traditional three-phase glass capillary device (Utada et al., 2005; Nabavi et al., 2015), the inner and middle fluids are immiscible, leading to the generation of core-shell droplets whose core and shell regions are composed of the inner and middle fluid, respectively. Recently, three-phase capillary device was used to form Janus and patchy polymer particles by mixing two streams of miscible polymer solutions within droplets (Ekanem et al., 2017). However, to the best of our knowledge, this device has never been used to synthesise nanoparticles. Glass capillary devices are more stable against particle deposition than 2D flow focusing droplet generators (Filatov et al., 2016), due to axisymmetric geometry of coaxial capillaries, which confines droplets to the central axis of the collection channel and minimises their contacts with the channel walls. The carrier fluid was environmentally friendly organic liquid Miglyol 840 instead of commonly used toxic fluorinated solvents (Tice et al., 2003).

\section{Methodology}

\subsection{Chemicals and solutions}

The gold precursor was $1 \mathrm{mM}$ solution of tetrachloroauric acid trihydrate $\left(\mathrm{HAuCl}_{4} \cdot 3 \mathrm{H}_{2} \mathrm{O}\right.$, $\geq 99.9 \%$ trace metals basis, Sigma Aldrich, UK) containing $1 \%(\mathrm{w} / \mathrm{v})$ of polyvinylpyrrolidone (PVP K30, $\mathrm{M}_{\mathrm{w}} \sim 40,000 \mathrm{~g} / \mathrm{mol}$, Sigma Aldrich, UK) as a capping agent for AuNPs. The reducing agent was $20 \mathrm{mM}$ L-ascorbic acid (reagent grade, Sigma Aldrich, UK) at pH 2.9. In some trials the $\mathrm{pH}$ of the ascorbic acid stream was adjusted to $\mathrm{pH} 10.3$ using $2 \mathrm{M} \mathrm{NaOH}$ (Fisher Scientific, UK). The carrier fluid was Miglyol 840, a mixture of propylene glycol diesters of caprylic and capric acids, donated by Sasol Germany GmbH. Octadecyltrimethoxysilane (Sigma Aldrich, UK) and 2-[methoxy(polyethyleneoxy)propyl] trimethoxysilane (Fluorochem Ltd, UK) were used for hydrophobic and hydrophilic surface treatment of glass capillaries, respectively. Aqua regia prepared by mixing $2 \mathrm{ml}$ of $36 \% \mathrm{HNO}_{3}$ and $8 \mathrm{ml}$ of $70 \% \mathrm{HCl}$ was used to clean the glassware. All the aqueous solutions were prepared using Milli-Q water generated using the Millipore 185 Milli-Q Plus unit.

\subsection{Device fabrication and experimental setup}

Borosilicate round glass capillaries (1.0 mm OD, $0.58 \mathrm{~mm}$ ID, Intracel, UK) were pulled using a P-97 micropipette puller (Sutter Instrument Company, USA). The orifice diameters of tapered 
tube ends were adjusted to $50 \mu \mathrm{m}$ for the injection capillary and $300 \mu \mathrm{m}, 200 \mu \mathrm{m}$, and $150 \mu \mathrm{m}$ for the collection capillary using a Narishige model MF-830 micro-forge. The tips of the injection and collection capillary tubes were rendered hydrophilic and hydrophobic respectively with corresponding silanes. The salinized capillaries were inserted into a square borosilicate glass capillary $(5 \mathrm{~cm}$ length, $1.05 \pm 0.1 \mathrm{~mm}$ inner width, $0.2 \mathrm{~mm}$ wall thickness, Atlantic International Technologies, USA), coaxially aligned on a microscope slide and fixed in place using Devcon 5 Minute Epoxy glue. Three hypodermic needles were glued at entry sections of the capillaries (Figure 1a) and Portex ${ }^{\mathrm{TM}}$ fine bore polyethylene medical tubing (0.86 mm ID, Smiths Medicals, UK) was attached to the needles to deliver fluids to the device. PVC tubing with $1 \mathrm{~mm}$ OD was attached to the collection capillary to collect the product stream from the device (Figure 1b).
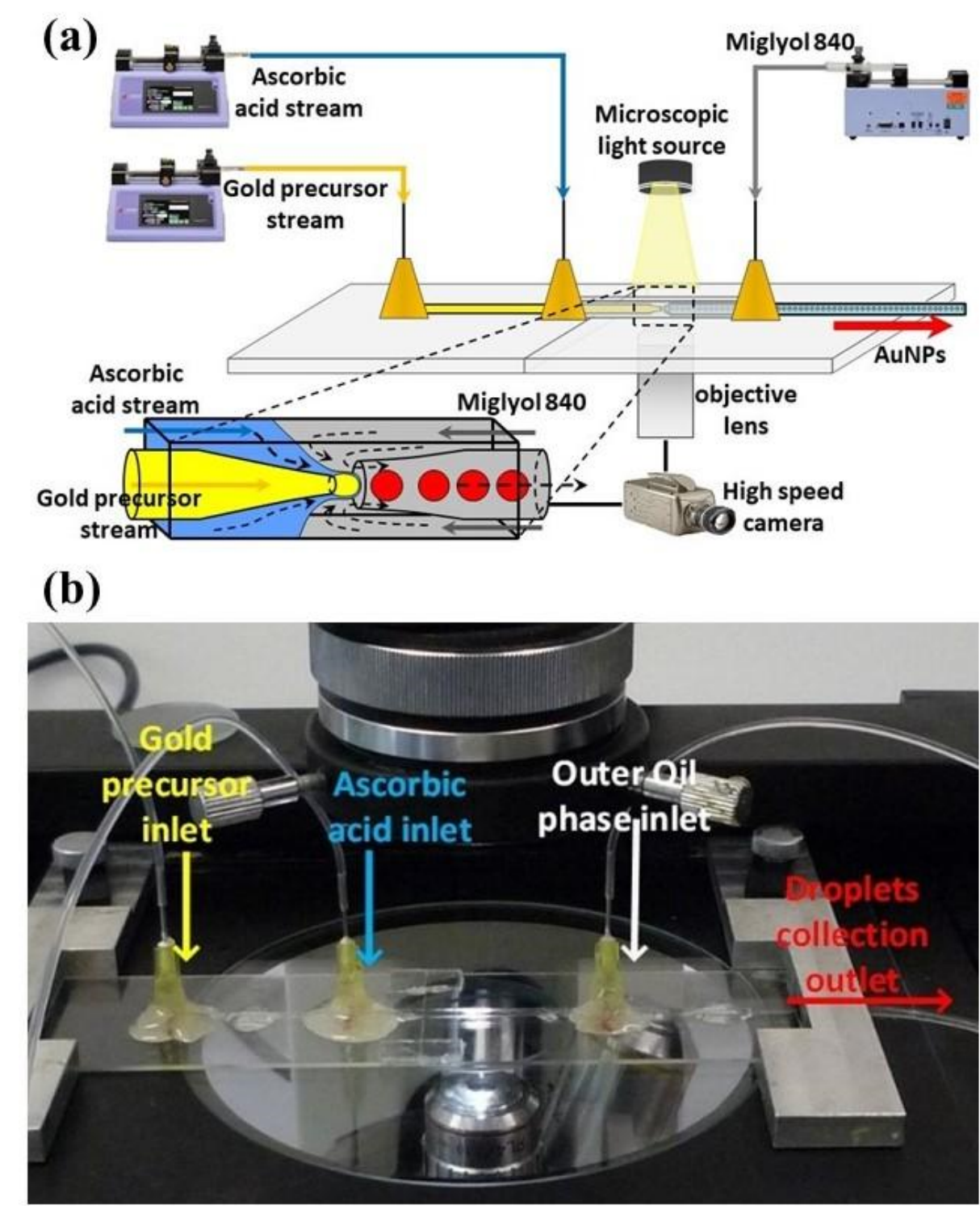

Figure 1. (a) Schematic diagram of the experimental setup and a magnified image of the flow focusing region inside the glass capillary device; (b) Photograph of the glass capillary device connected to the medical tubing and mounted on the microscope stage. 


\subsection{Experimental procedure}

The device was placed on the microscope stage and the $\mathrm{HAuCl}_{4}$, ascorbic acid, and Miglyol streams were delivered at constant flow rates from $10 \mathrm{ml}, 25 \mathrm{ml}$, and $50 \mathrm{ml} \mathrm{SGE}$ gas tight syringes using Harvard Apparatus 11 Elite pumps. The drop generation was observed using a XD63 optical inverted microscope (GX Microscopes, USA) and Phantom V9.0 high speed camera (Vision Research, USA), as shown in Figure 2(a). The dimensions of the device and droplet size were measured using ImageJ program. Figure 2(b) illustrates the flow pattern inside the device. The reactants streams were merged together just before the droplets were formed.

(a)

(b)

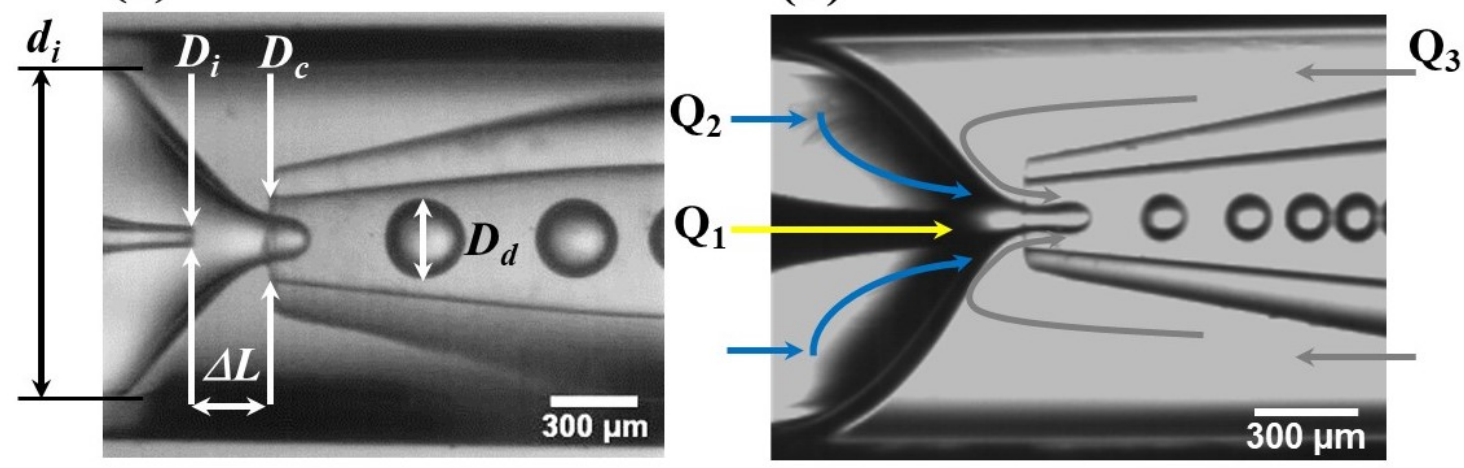

Figure 2. Micrographs of fluid flows and drop generation: (a) Geometry of the device, where $d_{i}$ is the inner height of the outer capillary, $D_{i}$ is the inner diameter of the injection orifice, $D_{c}$ is the inner diameter of the collection orifice, $\Delta L$ is the distance between the injection and collection orifice, and $D_{d}$ is the droplet diameter; (b) Flow pattern inside the device, where yellow arrow is the gold precursor stream $\left(Q_{1}\right)$, blue arrows are the ascorbic acid stream $\left(Q_{2}\right)$ and grey arrows are the carrier oil stream $\left(Q_{3}\right)$.

\subsection{Particle characterisation}

Dynamic light scattering (DLS). The mean particle size and polydispersity index (PDI) of AuNPs were measured by DLS using a Delsa ${ }^{\mathrm{TM}}$ Nano HC particle size analyser (Beckman Coulter, UK). As the continuous oil phase was used without a lipophilic surfactant, the aqueous phase containing AuNPs and the continuous phase were separated by gravity settling inside the collection vial due to the differences in density between Miglyol 840 and water. Due to their hydrophilicity, PVP-capped AuNPs were dispersed in the aqueous phase, which formed a bottom layer in the vial. $\sim 3 \mathrm{ml}$ of the aqueous suspension of AuNPs was then transferred to a disposable polyethylene cuvette and placed inside the analyser, which was illuminated by a laser beam. Time-dependent fluctuations in intensity of scattered light, due to Brownian motion of the NPs, were measured by a fast photon detector at a scattering angle of $165^{\circ}$ over $90 \mathrm{~s}$. The mean particle size and PDI were obtained as the average values of 3 repeated measurements. 
Transmission Electron Microscopy (TEM). A drop of AuNPs suspension of $10 \mu 1$ volume was placed onto a holey carbon-coated copper grid (EM Resolutions Ltd, UK) and dried overnight. The analysis was carried out using a JEOL 2000FX TEM operated at an accelerating voltage of $200 \mathrm{kV}$.

Ultraviolet-visible (UV-Vis) spectroscopy. The UV-Vis absorbance spectra of the AuNPs suspensions were measured using a Perkin Elmer Lambda $35 \mathrm{UV}-\mathrm{V}$ is spectrometer fitted with deuterium and tungsten-halogen lamps to provide UV and visible range of electromagnetic wavelengths. Two disposable polyethylene cuvettes containing $\sim 3 \mathrm{ml}$ of the product sample and the reference sample (Milli Q water) were placed inside the instrument. The incident light with a wavelength ranging from 300 to $800 \mathrm{~nm}$ was split into two equal beams which passed through each sample. The intensity of the transmitted light was measured by a photodiode detector. The absorbance spectrum of the product was determined from the Beer-Lambert's law by comparing the intensities of the two transmitted beams. The colour of suspended AuNPs depends on their particle size, surface properties and concentration (Verma et al., 2014). Therefore, the size and concentration of AuNPs was estimated from their UV-Vis absorption spectra.

Droplet diameter. The droplet generation inside the microfluidic device was recorded by the high-speed camera at 2000 frames per second and $576 \times 288$ resolution. Commercially available ImageJ software from the National Institutes of Health was used to characterise the generated droplets by measuring 20 or more droplets and calculating their mean diameter.

\section{Results and discussion}

AuNPs were formed by reduction of tetrachloroaurate (III) with ascorbic acid (Tyagi et al., 2011; Vasilescu et al., 2012) triggered by mixing two streams within droplets:

$2 \mathrm{AuCl}_{4}^{-}+3 \mathrm{C}_{6} \mathrm{H}_{8} \mathrm{O}_{6} \rightarrow 2 \mathrm{Au}^{0}+3 \mathrm{C}_{6} \mathrm{H}_{6} \mathrm{O}_{6}+8 \mathrm{Cl}^{-}+6 \mathrm{H}^{+}$

The molar ratio of $\mathrm{HAuCl}_{4}$ to $\mathrm{C}_{6} \mathrm{H}_{8} \mathrm{O}_{6}$ of 1:120 was maintained in all experiments. This molar ratio of the two reactants was found to lead to smallest AuNPs in our previous study carried out using co-flow device with two continuous fluid streams (Bandulasena et al., 2017). 


\subsection{Control of droplet size}

Droplet size has a significant impact on the mixing efficiency within a droplet. In glass capillary devices, droplet size can be adjusted by controlling the geometry of the capillary tubes and fluid flow rates. Gañán-Calvo and Gordillo (2001) have found a simple scaling law that can be used to predict the diameter of gas bubbles, $D_{b}$ formed in dripping regime when a gas stream with a flow rate of $Q_{g}$ is forced to flow through a small orifice driven by an outer liquid stream: $D_{b} / D \propto\left(Q_{l} / Q_{g}\right)^{-x}$, where $D$ is the orifice diameter and $Q_{l}$ is the liquid flow rate. The validity of this relation has been proved for generation of bubbles in planar PDMS microfluidic devices (Garstecki et al., 2005) and for emulsion formation in glass capillary devices (Vladisavljević et al., 2012). In this study, the dispersed phase was formed by merging gold salt stream with a flow rate of $Q_{1}$ and ascorbic acid stream with a flow rate of $Q_{2}$. Therefore, $Q_{g}$ will be replaced by $Q_{1}+Q_{2}$, while $Q_{l}$ will be replaced by the Miglyol flow rate, $Q_{3}$, to give the scaling law:

$D_{d} / D_{c} \propto\left[Q_{3} /\left(Q_{1}+Q_{2}\right)\right]^{-x}$

where $D_{d}$ and $D_{c}$ are the droplet diameter and the collection orifice diameter respectively. In Figure 3, the experimental $D_{d} / D_{c}$ values obtained in dripping regime were plotted against $Q_{3} /\left(Q_{1}+Q_{2}\right)$ using a log scale. The results follow a good linear trend and the equation of the best-fit straight line applicable for all orifice diameters of the collection tube is:

$D_{d} / D_{c}=1.36\left[Q_{3} /\left(Q_{1}+Q_{2}\right]^{-0.42}\right.$

The value of $x$ in Eq. (3) of 0.42 is consistent with 0.4 reported by Garstecki et al. (2005) and 0.37 obtained by Gañán-Calvo and Gordillo (2001). The accuracy of the parameters in Eq. (3) is $\pm 15 \%$ since the equation does not include physical properties of the fluids, which also has an impact on droplet size. The reaction mixture undergoes a chemical reaction followed by particle nucleation and growth inside droplets, which may cause the interfacial tension to change as the synthesis of AuNPs is progressing, due to the particle adsorption at liquid-liquid interface (Rana et al., 2012). The binding energy of NPs associated with their adsorption to the interface depends on the composition of the oil and aqueous phase (Du et al., 2010). Eq. (3) is valid only in dripping regime when monodisperse droplets are formed, i.e. for relatively low Capillary numbers of the oil phase $\left(\mathrm{Ca}_{3}\right)$ and low Weber numbers of the reaction mixture $\left(W e_{1+2}\right)$. Physical properties of the oil phase and aqueous phase affect the resulting droplet size and the transition from dripping to jetting regime and therefore, Eq. (3) is valid only for the emulsion 
formulation used in this study. Higher viscosity of the oil phase should lead to higher flow focusing effect in the collection capillary and this should result in smaller reaction droplets for the same fluid flow rates. However, the effect of oil viscosity was not investigated in this work.

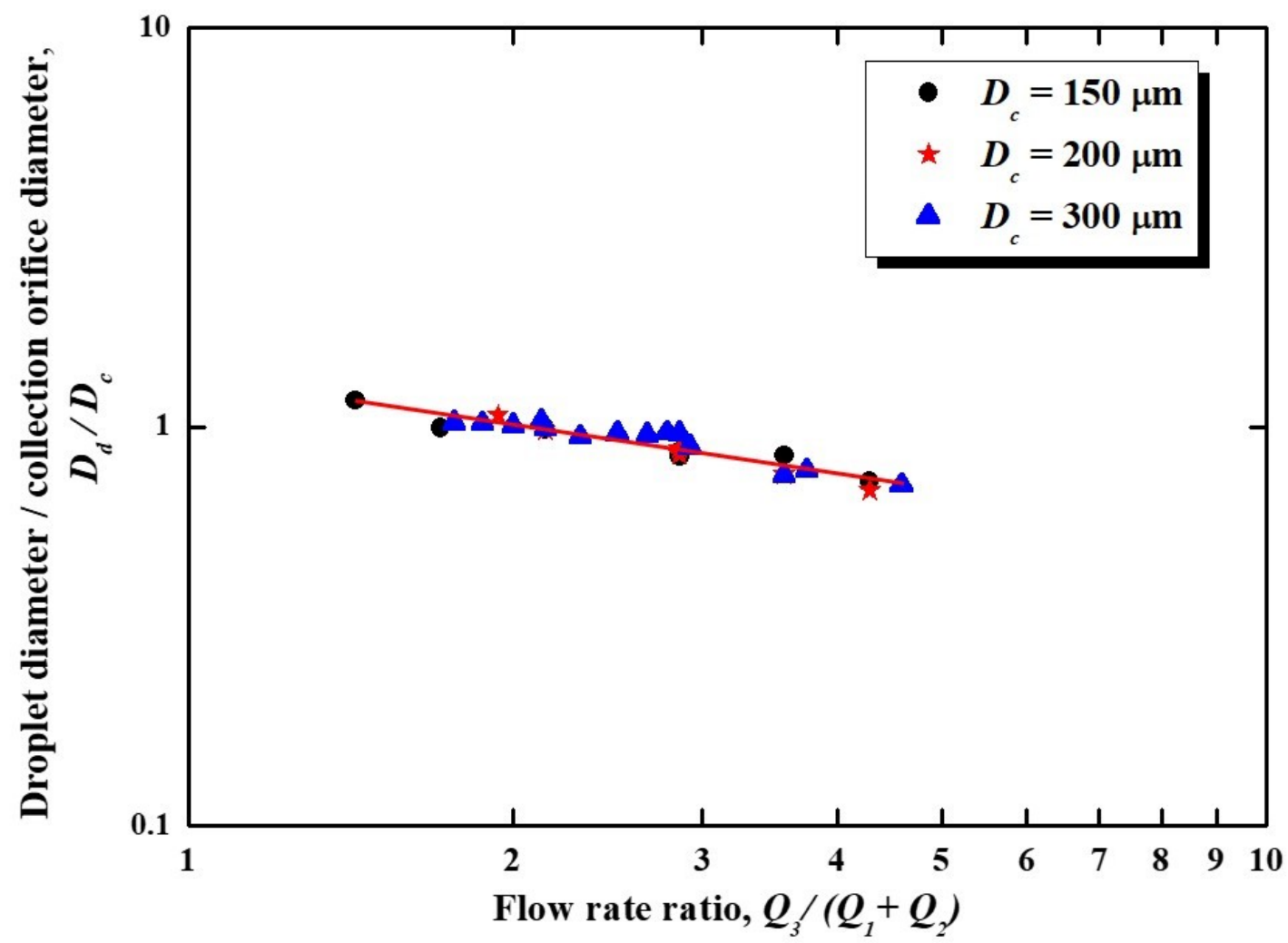

Figure 3. The ratio of the droplet diameter to collection orifice diameter, $D_{d} / D_{c}$, as a function of the volumetric flow rate ratio, $Q_{3} /\left(Q_{1}+Q_{2}\right)$, for drop generation in dripping regime. $\Delta L=$ $0.5 D_{c}, Q_{1}=1-5 \mathrm{ml} / \mathrm{h}, Q_{2}=4-12 \mathrm{ml} / \mathrm{h}, Q_{3}=10-60 \mathrm{ml} / \mathrm{h}$.

\subsection{Effect of oil phase flow rate on the size of droplets and AuNPs}

In this section, the synthesis of AuNPs was performed at $\mathrm{pH} 10.3$ in the device with $D_{i}=50 \mu \mathrm{m}$ and $D_{c}=300 \mu \mathrm{m}$ at four different oil flow rates ranging between 30 and $60 \mathrm{ml} / \mathrm{h}$.

As shown in Figures 4 and 5, smaller AuNPs were obtained by smaller droplets, probably due to better mixing in smaller droplets (Song et al., 2006), because the rate of diffusion is inversely proportional to the distance through which the reactants are diffusing. In addition, smaller droplets were formed through more intense shearing of the interface due to higher flow rate of the carrier oil, which led to more pronounced circulating flows inside the droplets. 
(a)
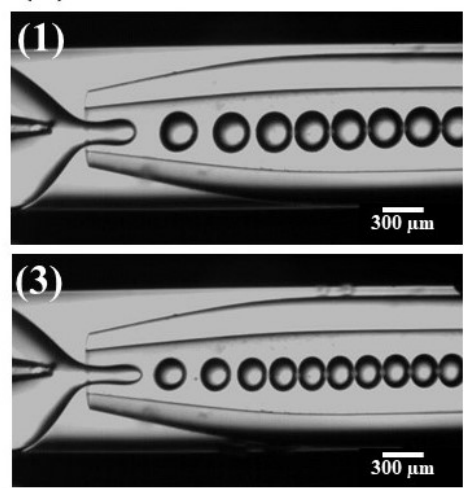
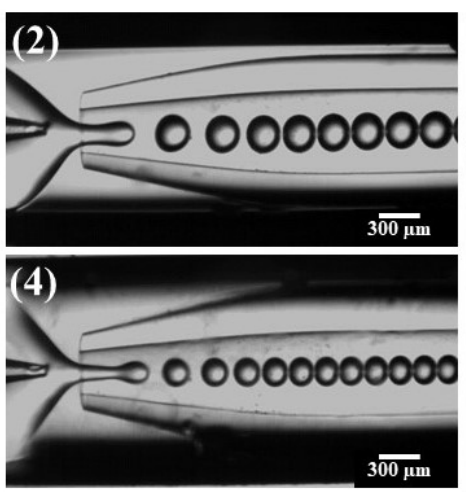

(b)
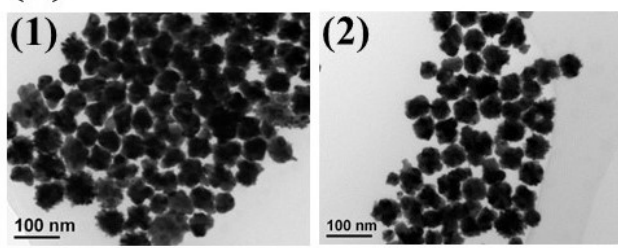

(3)

(4)

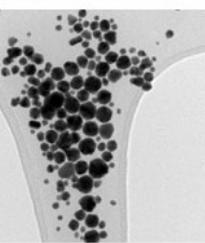

Figure 4. (a) Generation of reaction droplets at $Q_{1}=2 \mathrm{ml} / \mathrm{h}, Q_{2}=12 \mathrm{ml} / \mathrm{h}$, and $Q_{3}:$ (1) $30 \mathrm{ml} / \mathrm{h}$; (2) $40 \mathrm{ml} / \mathrm{h}$; (3) $50 \mathrm{ml} / \mathrm{h}$; (4) $60 \mathrm{ml} / \mathrm{h}$. (b) TEMs of the AuNPs synthesized using droplets shown in (a1), (a2), (a3) and (a4) respectively: (b1) $P D I=0.181$; (b2) $P D I=0.186$; (b3) $P D I=0.228$; (b4) $P D I=0.232$. The device geometry: $\Delta L=150 \mu \mathrm{m}, D_{i}=50 \mu \mathrm{m}$, and $D_{c}=300 \mu \mathrm{m}$. The $\mathrm{pH}$ of the ascorbic acid solution was 10.3. The particle sizes are shown in Figure 5.

Due to better mixing of reactant streams in smaller droplets, particle nucleation dominated over particle growth, which led to higher polydispersity of the AuNPs in smaller droplets, because nucleation is more stochastic process than particle growth. Indeed, the PDI of the AuNPs increased from 0.181 to 0.232 when the droplet size was reduced from $275 \mu \mathrm{m}$ to $196 \mu \mathrm{m}$ (Figure 4). The TEM and DLS particle diameters show the same trend proving that smaller NPs were generated at higher oil flow rates, due to more vigorous mixing in droplets. TEM particle diameters were consistently smaller than DLS results, probably due to collapse of the hydrated PVP layer around the NPs during drying, which was performed prior to TEM measurements. DLS measures the hydrodynamic diameter of AuNPs in a nano-suspension, which includes hydrated PVP shell around the particles (Ellis et al., 2017; Fissan et al., 2014). The thickness of the hydrated stabiliser layer is $18-24 \mathrm{~nm}$, estimated from the difference between the TEM and DLS diameters.

In Figure 4 and 5, the droplet size was manipulated by changing the Miglyol flow rate between 30 and $60 \mathrm{ml} / \mathrm{h}$. When the oil flow rate exceeded $60 \mathrm{ml} / \mathrm{h}$, some droplets started to merge in the collection tube to generate bigger droplets. Droplet coalescence is undesirable, because it leads to polydispersed droplets and heterogeneous mixing conditions in droplets. To generate smaller, monodispersed droplets at moderate Miglyol flow rates, a collection tube with the smaller orifice size must be used. 


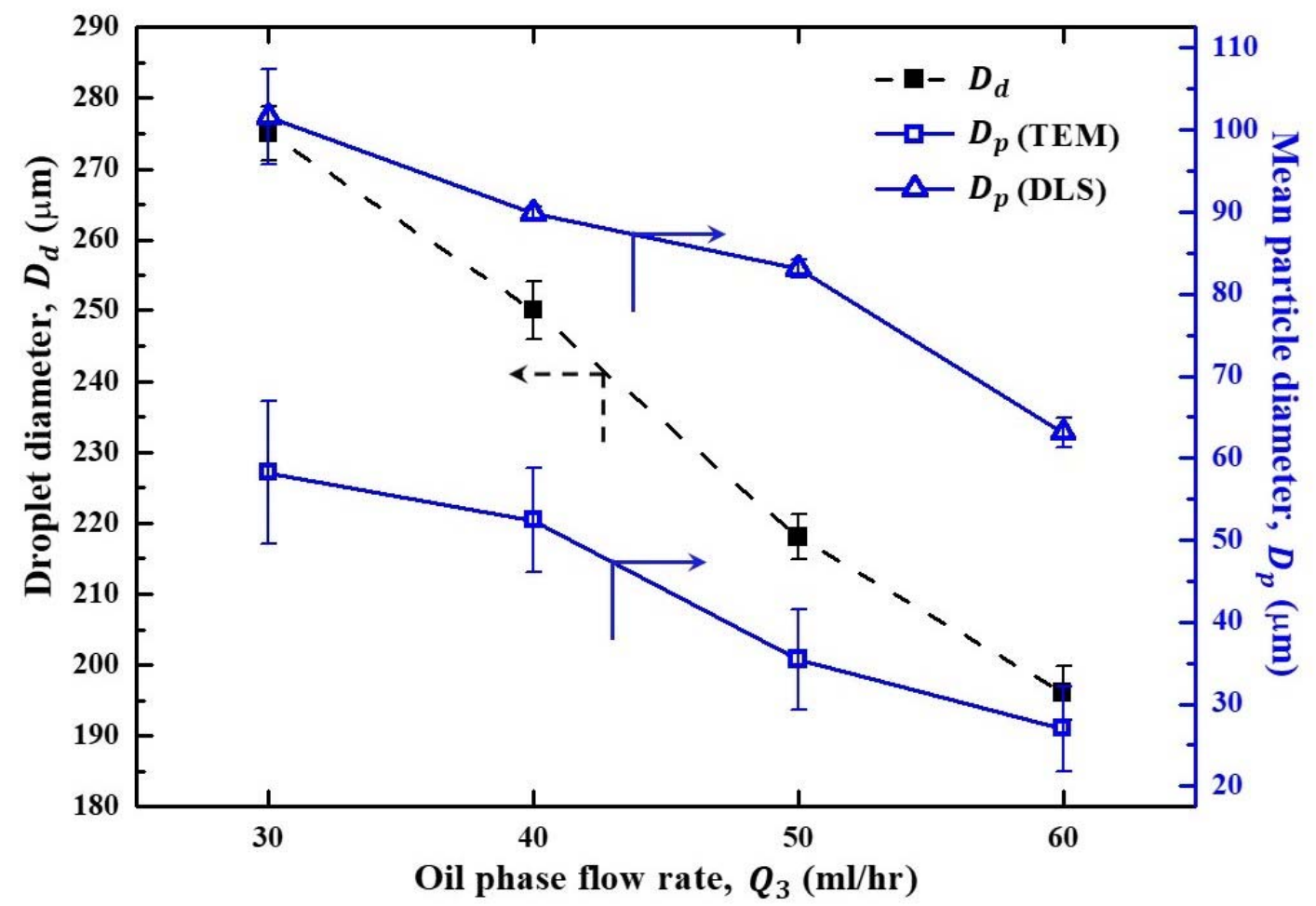

Figure 5. The average size $D_{p}$ of the synthesised AuNPs measured using DLS and TEM, and the average size $D_{d}$ of the reaction droplets. The flow rates and the device geometry were the same as in Figure 4.

\subsection{Effect of the orifice size of the collection tube on the size of droplets and AuNPs}

In this section, reaction droplets were generated using three different orifice sizes of the collection tube at the constant oil to aqueous phase flow rate ratio of $2: 14$. The flow rate ratio of the ascorbic acid to $\mathrm{HAuCl}_{4}$ stream was also kept constant at 6. Droplets were highly uniform in all cases (Figure 6). Smaller $D_{c}$ values led to smaller droplets and smaller AuNPs. It should be noticed that the DLS-measured average size of AuNPs was in the range of $79-141 \mathrm{~nm}$ and $63-102 \mathrm{~nm}$ at $\mathrm{pH}=2.9$ (Figure 6) and $\mathrm{pH}=10.3$ (Figure 5), respectively. Ascorbic acid deprotonates into two different ionic species, $\mathrm{HASC}^{-}$and $\mathrm{AsC}^{2-}$, depending on the $\mathrm{pH}$ :

$$
\begin{aligned}
& H_{2} A s c \leftrightarrow H A s c^{-}+H^{+} ; K_{a 1}=7.9 \times 10^{-5}, p K_{a}=4.1 \\
& H A s c^{-} \leftrightarrow A s c^{2-}+H^{+} ; K_{a 2}=1.6 \times 10^{-12}, p K_{a}=10.8
\end{aligned}
$$

At $\mathrm{pH}=2.9$, the dominant form is $H_{2} A s c$, which has a weak reducing power due to its low $\mathrm{pKa}$ value of 4.1. Hence, the redox reaction (1) was slow, which led to small number of nucleation sites and relatively large AuNPs. At $\mathrm{pH}=10.3, \sim 78 \%$ of ascorbic acid is in the form of $\mathrm{HAsc}^{-}$ 
and $\sim 22 \%$ is in the form of $A s c^{2-}$ ions, which both have much stronger reducing power than undissociated molecules, leading to faster redox reaction and smaller AuNPs. In the reminder of this work, the $\mathrm{pH}$ of ascorbic acid stream was fixed at 2.9 to minimise the formation of AuNPs before the droplets were formed.

(a)

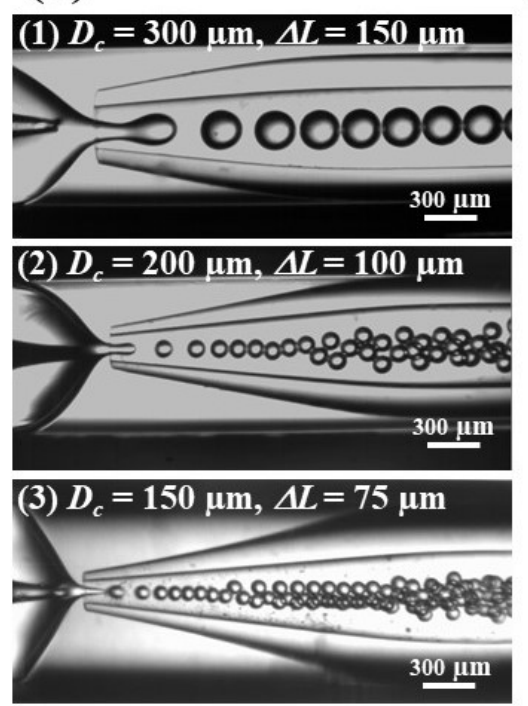

(b)

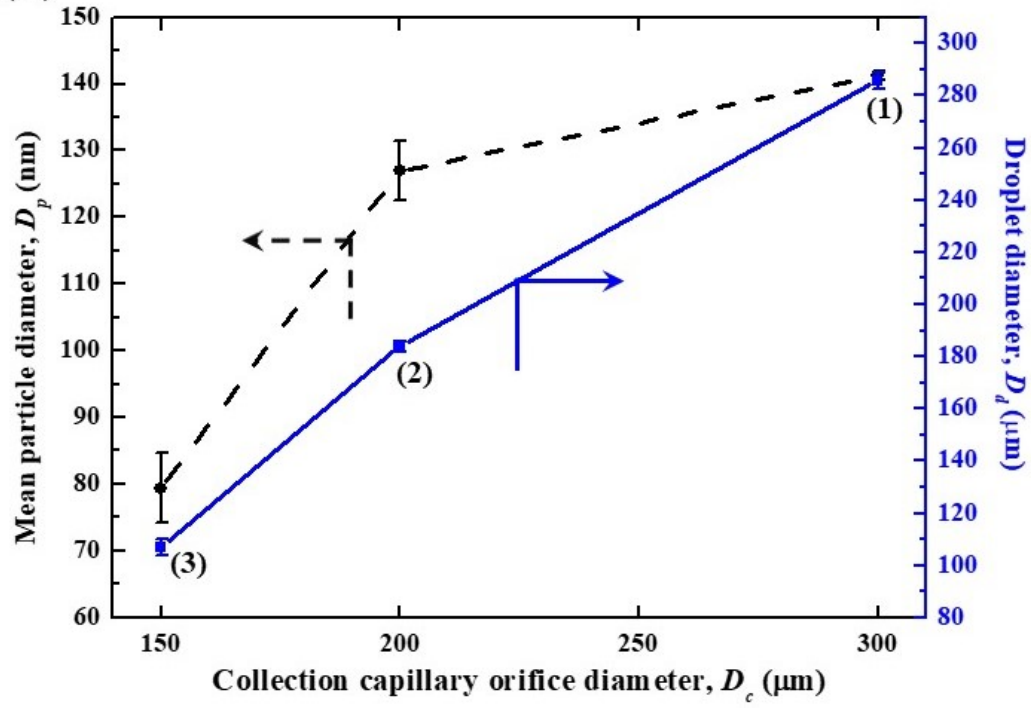

Figure 6. (a) Droplet generation in the devices with different orifice sizes $D_{c}$ of the collection capillary tube at $Q_{3} /\left(Q_{1}+Q_{2}\right)=2.14$ and $Q_{2} / Q_{1}=6$; (b) The effect of $D_{c}$ on the average droplet size as measured by DLS and the average size of synthesised AuNPs at $Q_{3} /\left(Q_{1}+Q_{2}\right)$ $=2.14$ and $Q_{2} / Q_{1}=6$. The $\mathrm{pH}$ of the ascorbic acid stream was 2.9.

In the next section, the orifice size of the collection tube was kept constant, as well as the total flow rate of the two reactant streams, but their flow rate ratio was varied.

\subsection{Effect of the inner and middle phase flow rates on the size of AuNPs}

To investigate the effect of reactant stream flow rates on the size of AuNPs, the flow rate ratio of gold salt stream to ascorbic acid stream was gradually increased from 2 to $12 \mathrm{ml} / \mathrm{h}$ to 8 to 6 $\mathrm{ml} / \mathrm{h}$, keeping the total flow rate of the two streams constant at $14 \mathrm{ml} / \mathrm{h}$. Four different flow rate combinations of the reactant streams were explored, each at two different oil flow rates (Fig. 7a). The size of AuNPs obtained in a co-flow device was provided for comparison. The TEM images of all 8 samples were provided in Fig. $7 \mathrm{~b}$.

Smaller AuNPs were prepared when the flow rate ratio $Q_{1} / Q_{2}$ was higher. Increasing $Q_{1} / Q_{2}$ will increase the velocity of the gold precursor stream exiting the injection nozzle and reduce the velocity of the ascorbic acid stream. The difference in velocities of these two streams 
induces a dipole-like (known as Hill's spherical vortex) mixing inside generated droplets, enhancing mass transfer (Grigoriev et al., 2006). The size of AuNPs produced in a co-flow capillary device was considerably larger (Fig. 7a) due to less efficient mixing of reactants in parallel continuous streams than in droplets and more pronounced particle growth triggered by the deposition of the NPs onto the wall of the collection capillary.

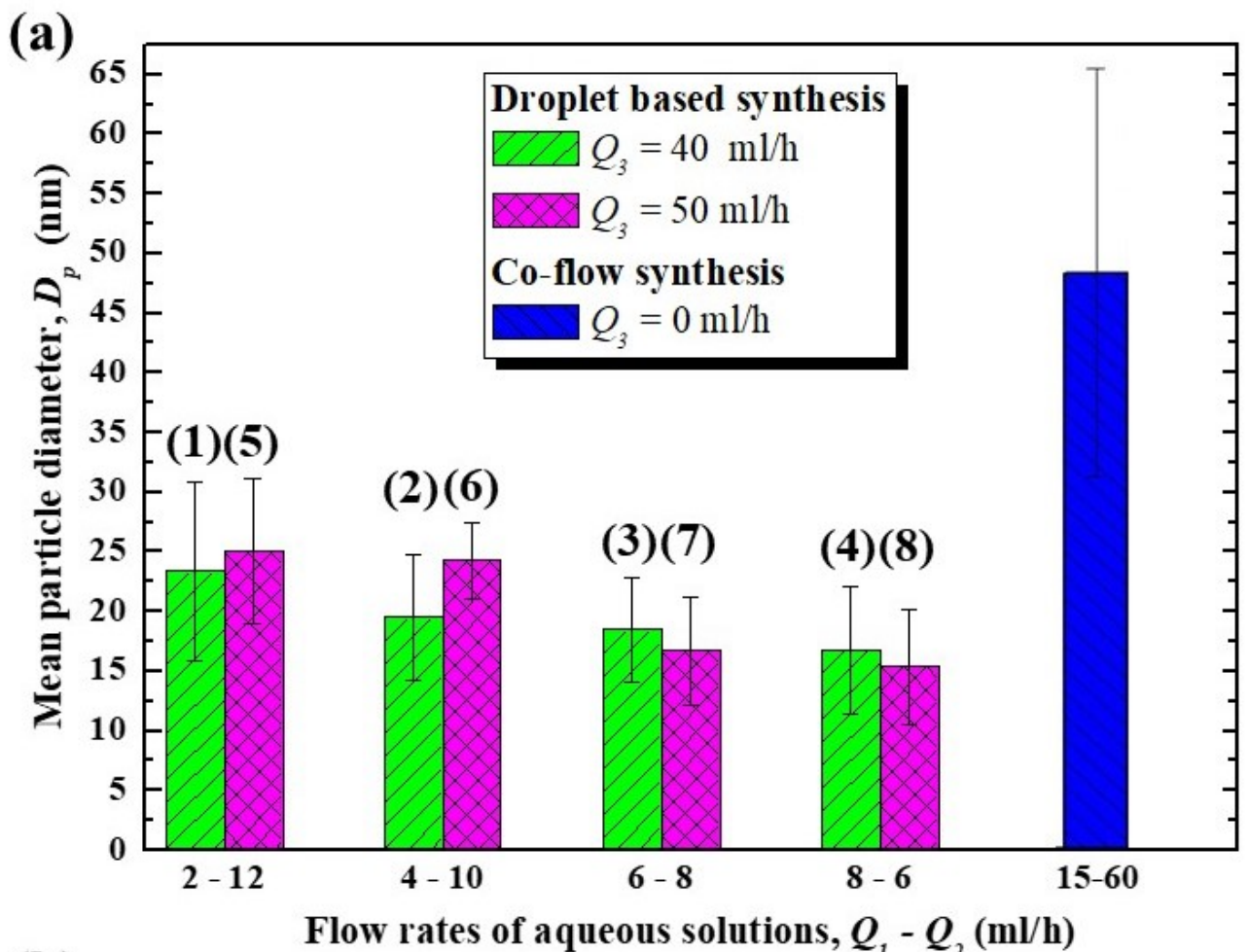

(b)
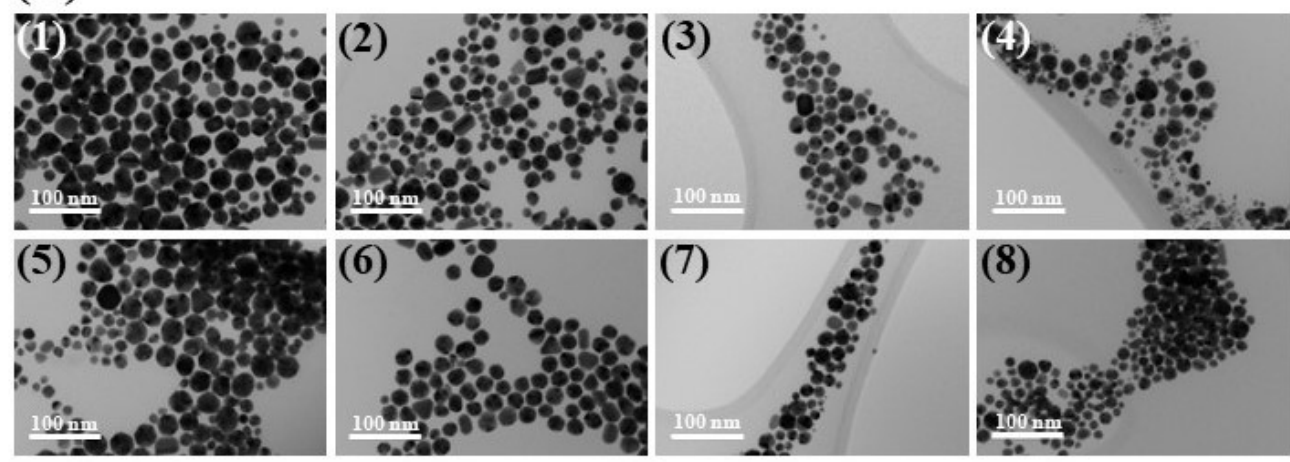

Figure 7. (a) The size of the synthesised AuNPs as a function of flow rate ratio of the two reactant streams, $Q_{1}$ and $Q_{2}$, at two different oil flow rates, $Q_{3}=40$ and $50 \mathrm{ml} / \mathrm{h}\left(D_{i}=50 \mu \mathrm{m}\right.$, $\left.D_{c}=300 \mu \mathrm{m}, Q_{1}+Q_{2}=14 \mathrm{ml} / \mathrm{h}\right)$. The size of AuNPs obtained in a co-flow device $\left(Q_{3}=0\right)$ at the same reactant concentrations was provided for comparison $\left(D_{i}=100 \mu \mathrm{m}, \mathrm{pH}\right.$ of ascorbic acid stream $=10.2 \pm 0.3, Q_{1}=15 \mathrm{ml} / \mathrm{h}, Q_{2}=60 \mathrm{ml} / \mathrm{h}$ ). (b) TEMs of AuNPs produced at $Q_{3}=$ $40 \mathrm{ml} / \mathrm{h}$ (labels $1,2,3$, and 4) and $Q_{3}=50 \mathrm{ml} / \mathrm{h}$ (labels 5, 6, 7, and 8). 
3.5 Effect of the distance between two inner capillaries $(\Delta L)$ on the size of droplets and AuNPs

Fig. 8a-c shows the micrographs of reaction droplets formed under the same flow rates, but at different distances between the inner capillaries, $\Delta L$. When $\Delta L>0$ (Fig. 8a) and $\Delta L<0$ (Fig. 8c), generated droplets were slightly bigger than when $\Delta L=0$ (Fig. 8b), due to the lower shear from the surrounding oil phase. The smallest droplets were generated when the positions of the two orifices coincided, because the reaction mixture experienced the highest shear (Nabavi et al., 2017). Fig. 8d shows the UV-Vis absorption spectra of the prepared AuNPs. The absorption peak was shifted towards shorter wavelengths when the distance between the tips of the two capillaries was reduced from $200 \mu \mathrm{m}$ to zero in either direction, confirming that the smallest AuNPs were formed at zero gap. It can be explained by the smallest droplets and the highest shear at $\Delta L=0$, which led to the most intense internal flows and the most efficient mixing within droplets. The maximum peak height in Fig. $8 \mathrm{~d}$ was observed at $\Delta L=0$, due to the highest particle concentration achieved at the minimum particle size. The amount of AuNPs was the same in all samples due to the same flow rates and initial reactant concentrations, which means that the sample with the smallest AuNPs showed the maximum peak height.
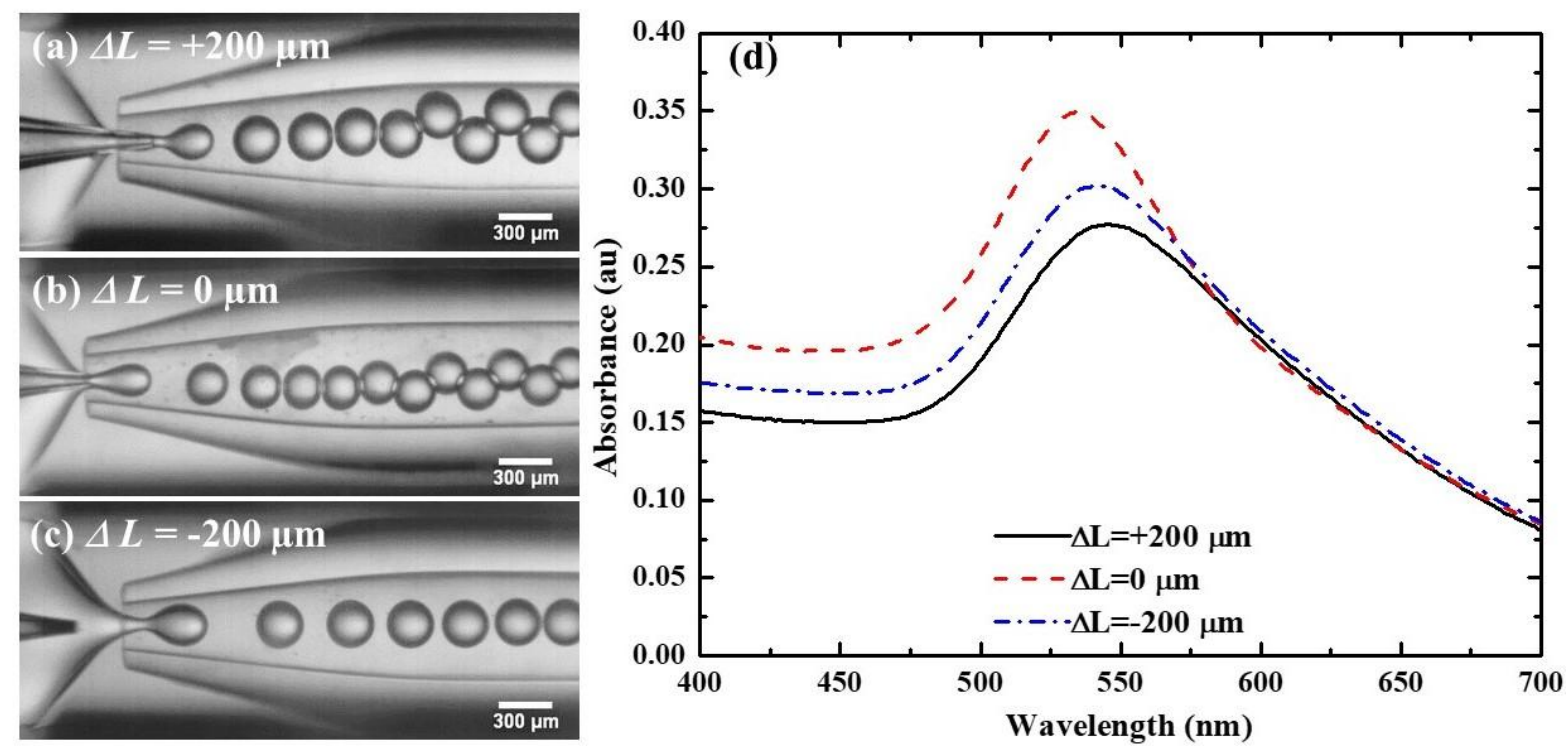

Figure 8. Formation of reaction droplets at three different positions of the inner capillaries: (a) $\Delta L=+200 \mu \mathrm{m}$; (b) $\Delta L=0$; (c) $\Delta L=-200 \mu \mathrm{m}$. The plus sign indicates that the injection tube is inserted into the collection tube downstream of the entry section; (d) UV-visible absorbance spectra of the synthesised AuNPs. Other conditions: $Q_{1}=2 \mathrm{ml} / \mathrm{h}, Q_{2}=12 \mathrm{ml} / \mathrm{h}, Q_{3}=30 \mathrm{ml} / \mathrm{h}$, $D_{i}=50 \mu \mathrm{m}$, and $D_{c}=300 \mu \mathrm{m}$. 


\subsection{Reactor fouling mitigation}

The use of droplet-based microfluidic device eliminated fouling of the collection capillary, since the carrier oil acted as a barrier between the reaction droplets and the reactor walls preventing deposition of the AuNPs. The operating time of the device was more than $2.5 \mathrm{~h}$ without reactor fouling. The injection nozzle started to experience fouling after several hours because it was in direct contact with the reaction mixture, but it was mitigated by using lower $\mathrm{pH}$ in the reaction mixture to delay nucleation until the droplets were formed.

\section{Conclusion}

A novel method of chaotic mixing of aqueous reactant streams within droplets formed in an environmentally friendly organic liquid by combination of co-flow and hydrodynamic flow focusing was developed and investigated using three-phase glass capillary microfluidic device. The manipulation of reagent flow rates and capillary dimensions/geometry resulted in a precise control of the size of generated droplets and nanoparticles. A higher flow rate of the carrier oil resulted in smaller droplets due to larger shear stresses exerted on the interface, which led to more efficient mixing within droplets and smaller size of synthesised AuNPs. Smaller droplets were also generated by reducing the orifice size of the collection capillary tube. Large difference in velocities between the gold precursor stream injected through the inner capillary and the ascorbic acid stream supplied co-currently through the outer capillary created strong internal flows, which led to improved mixing and smaller AuNPs. The highest shear on the liquid interface at the outlet of the injection capillary led to the smallest AuNPs and the highest absorption peak was observed in the UV-Vis spectrum. Droplet-based micro-reactor used in this study achieved smaller AuNPs than the previously reported co-flow capillary device with two continuous reactant streams (Bandulasena et al., 2017), which can be attributed to smaller diffusional distances in the droplet-based reactor, more efficient mixing within the droplets and mitigation of reactor fouling by employing hydrophobic barrier between the reaction mixture and the reactor walls. Assuming $100 \%$ conversion of $\mathrm{HAuCl}_{4}$ to $\mathrm{AuNPs}$ due to excess amount of ascorbic acid added, the particle concentration from $1.36 \times 10^{10} \mathrm{par} / \mathrm{ml}$ to $12.7 \times 10^{10} \mathrm{par} / \mathrm{ml}$ was achieved in the aqueous phase and the total weight of AuNPs produced after $2.5 \mathrm{~h}$ was 9.85 $\times 10^{-4} \mathrm{~g}$. When compared to the particle yield after $2.5 \mathrm{~h}$ of $0.01 \mathrm{mg}$ reported by Duraiswamy and Khan (2009), the particle productivity in this study was nearly 100 times higher. 
The mixing efficiency also depends on the size of the reaction droplets, stream flow rates, and the shear stress at the interface which can be controlled. The droplet-based microfluidic device offers enhanced flexibility and robustness such as variable on-demand flow rate ratio of the two aqueous reactant streams that impact the concentration of the reagents within the droplets and the reaction kinetics. This advantage allows rapid and flexible switching of reaction conditions without stopping the pumps or wasting valuable reagents. To further investigate the chaotic mixing inside reaction droplets and the reaction conversion achieved inside the droplets, a comprehensive computational fluid dynamics (CFD) study will be performed in the future.

\section{Acknowledgements}

The authors would like to thank Mr Jeff Nan for his assistance in experiments during his undergraduate research project and Dr Zhaoxia Zhou from the Loughborough Materials Characterization Centre (LMCC), Loughborough University, UK for her assistance in the TEM imaging. The microfluidic rig used in the project was purchased from the grant EP/J020184/1, funded by EPSRC, UK.

\section{References}

Bandulasena, M. V., Vladisavljević, G.T., Odunmbaku, O.G., Benyahia, B., 2017. Continuous synthesis of PVP stabilized biocompatible gold nanoparticles with a controlled size using a 3D glass capillary microfluidic device. Chem. Eng. Sci. 171, 233-243. doi:10.1016/j.ces.2017.05.035

Bannock, J.H., Krishnadasan, S.H., Heeney, M., de Mello, J.C., 2014. A gentle introduction to the noble art of flow chemistry. Mater. Horizons 1, 373. doi:10.1039/c4mh00054d

Casadevall i Solvas, X., Srisa-Art, M., DeMello, A.J., Edel, J.B., 2010. Mapping of fluidic mixing in microdroplets with 1 microsecond time resolution using fluorescence lifetime imaging. Anal. Chem. 82, 3950-6. doi:10.1021/ac100055g

deMello, A.J., 2006. Control and detection of chemical reactions in microfluidic systems. Nature 442, 394-402. doi:10.1038/nature05062

Du, K., Glogowski, E., Emrick, T., Russell, T.P., Dinsmore, A.D., 2010. Adsorption energy of nano- and microparticles at liquid-liquid interfaces. Langmuir 26, 12518-12522. doi:10.1021/la100497h

Duraiswamy, S., Khan, S.A., 2010. Nanoparticle Factories in Flowing Foams, in: Miniaturixed 
Systems for Chemistry and Life Sciences. pp. 1181-1183.

Duraiswamy, S., Khan, S.A., 2009. Droplet-based microfluidic synthesis of anisotropic metal nanocrystals. Small 5, 2828-2834. doi:10.1002/smll.200901453

Ekanem, E.E., Zhang, Z., Vladisavljević, G.T., 2017. Facile production of biodegradable bipolymer patchy and patchy janus particles with controlled morphology by microfluidic routes. Langmuir 33, 8476-8482. doi:10.1021/acs.langmuir.7b02506

Ellis, E., Zhang, K., Lin, Q., Ye, E., Poma, A., Battaglia, G., Loh, X.J., Lee, T.C., 2017. Biocompatible $\mathrm{pH}$-responsive nanoparticles with a core-anchored multilayer shell of triblock copolymers for enhanced cancer therapy. J. Mater. Chem. B 5, 4421-4425. doi:10.1039/C7TB00654C

Filatov, N.A., Belousov, K.I., Bukatin, A.S., Kukhtevich, I. V., Evstrapov, A.A., 2016. The study of mixing of reagents within a droplet in various designs of microfluidic chip. J. Phys. Conf. Ser. 741. doi:10.1088/1742-6596/741/1/012052

Fissan, H., Ristig, S., Kaminski, H., Asbach, C., Epple, M., 2014. Comparison of different characterization methods for nanoparticle dispersions before and after aerosolization. Anal. Methods 6, 7324-7334. doi:10.1039/c4ay01203h

Gañán-Calvo, A.M., Gordillo, J.M., 2001. Perfectly Monodisperse Microbubbling by Capillary Flow Focusing. Phys. Rev. Lett. 87, 274501. doi:10.1103/PhysRevLett.87.274501

Garstecki, P., Gañán-Calvo, A.M., Whitesides, G.M., 2005. Formation of bubbles and droplets in microfluidic systems. Bull. Polish Acad. Sci. 53, 361-372. doi:10.1007/978-90-4819029-4

Grigoriev, R.O., Schatz, M.F., Sharma, V., 2006. Chaotic mixing in microdroplets. Lab Chip 6, 1369-1372. doi:10.1039/b607003e

Horikoshi, S., Serpone, N., 2013. Chapter 1: Introduction to nanoparticles, in: Microwaves in Nanoparticle Synthesis: Fundamentals and Applications. John Wiley \& Sons, pp. 1-24. doi:10.1002/9783527648122

Huang, D., Liao, F., Molesa, S., Redinger, D., Subramanian, V., 2003. Plastic-compatible low resistance printable gold nanoparticle conductors for flexible electronics. J. Electrochem. Soc. 150, G412-417. doi:10.1149/1.1582466

Iwakoshi, A., Nanke, T., Kobayashi, T., 2005. Coating materials containing gold nanoparticles. Gold Bull. 38, 107-112. doi:10.1007/BF03215244

Kaminski, T.S., Garstecki, P., 2017. Controlled droplet microfluidic systems for multistep chemical and biological assays. Chem. Soc. Rev. 46, 6210-6226. doi:10.1039/c5cs00717h

Kim, D.K., Lai, Y., Diroll, B.T., Murray, C.B., Kagan, C.R., 2012. Flexible and low-voltage integrated circuits constructed from high-performance nanocrystal transistors. Nat. 
Commun. 3, 1-6. doi:10.1038/ncomms2218

Lee, J.-S., 2010. Recent progress in gold nanoparticle-based non-volatile memory devices. Gold Bull. 43, 189-199. doi:10.1007/BF03214986

Marre, S., Jensen, K.F., 2010. Synthesis of micro and nanostructures in microfluidic systems. Chem. Soc. Rev. 39, 1183. doi:10.1039/b821324k

Nabavi, S.A., Vladisavljević, G.T., Gu, S., Ekanem, E.E., 2015. Double emulsion production in glass capillary microfluidic device: Parametric investigation of droplet generation behaviour. Chem. Eng. Sci. 130, 183-196. doi:10.1016/j.ces.2015.03.004

Nabavi, S.A., Vladisavljević, G.T., Bandulasena, M. V, Arjmandi-Tash, O., Manović, V., 2017. Prediction and control of drop formation modes in microfluidic generation of double emulsions by single-step emulsification. J. Colloid Interface Sci. 505, 315-324. doi:https://doi.org/10.1016/j.jcis.2017.05.115

Nightingale, A.M., Phillips, T.W., Bannock, J.H., de Mello, J.C., 2014. Controlled multistep synthesis in a three-phase droplet reactor. Nat. Commun. 5, 3777-1-8. doi:10.1038/ncomms4777

Othman, R., Vladisavljević, G.T., Nagy, Z.K., 2015. Preparation of biodegradable polymeric nanoparticles for pharmaceutical applications using glass capillary microfluidics. Chem. Eng. Sci. 137, 119-130. doi:10.1016/j.ces.2015.06.025

Phapal, S.M., Sunthar, P., 2013. Influence of micro-mixing on the size of liposomes selfassembled from miscible liquid phases. Chem. Phys. Lipids 172-173, 20-30. doi:10.1016/j.chemphyslip.2013.04.006

Pissuwan, D., Niidome, T., Cortie, M.B., 2011. The forthcoming applications of gold nanoparticles in drug and gene delivery systems. J. Control. Release 149, 65-71. doi:10.1016/j.jconrel.2009.12.006

Rahman, M., Rebrov, E., 2014. Microreactors for gold nanoparticles synthesis: from faraday to flow. Processes 2, 466-493. doi:10.3390/pr2020466

Raj, V., Vijayan, A.N., Joseph, K., 2015. Cysteine capped gold nanoparticles for naked eye detection of E. coli bacteria in UTI patients. Sens. Bio-Sensing Res. 5, 33-36. doi:10.1016/j.sbsr.2015.05.004

Rana, S., Yu, X., Patra, D., Moyano, D.F., Miranda, O.R., Hussain, I., Rotello, V.M., 2012. Control of surface tension at liquid-liquid interfaces using nanoparticles and nanoparticleprotein complexes. Langmuir 28, 2023-2027. doi:10.1021/la204017z

Sarrazin, F., Prat, L., Di Miceli, N., Cristobal, G., Link, D.R., Weitz, D.A., 2007. Mixing characterization inside microdroplets engineered on a microcoalescer. Chem. Eng. Sci. 62, 1042-1048. doi:10.1016/j.ces.2006.10.013 
Shestopalov, I., Tice, J.D., Ismagilov, R.F., 2004. Multi-step synthesis of nanoparticles performed on millisecond time scale in a microfluidic droplet-based system. Lab Chip 4, 316-321. doi:10.1039/b403378g

Song, H., Chen, D.L., Ismagilov, R.F., 2006. Reactions in droplets in microfluidic channels. Angew. Chem., Int. Ed. 45, 7336-7356. doi:10.1002/anie.200601554

Song, Y., Hormes, J., Kumar, C.S.S.R., 2008. Microfluidic synthesis of nanomaterials. Small 4, 698-711. doi:10.1002/smll.200701029

Stone, Z.B., Stone, H.A., 2005. Imaging and quantifying mixing in a model droplet micromixer. Phys. Fluids 17, 1-11. doi:10.1063/1.1929547

Tice, J.D., Song, H., Lyon, A.D., Ismagilov, R.F., 2003. Formation of droplets and mixing in multiphase microfluidics at low values of the reynolds and the capillary numbers. Langmuir 19, 9127-9133. doi:10.1021/la030090w

Tyagi, H., Kushwaha, A., Kumar, A., Aslam, M., 2011. pH-dependent synthesis of stabilized gold nanoparticles using ascorbic acid. Int. J. Nanosci. 10, 857-860. doi:10.1142/S0219581X11009301

Utada, A.S., Lorenceau, E., Link, D.R., Kaplan, P.D., Stone, H.A., Weitz, D.A., 2005. Monodisperse double emulsions generated from a microcapillary device. Science 308, 537-541. doi:10.1126/science.1109164

Vasilescu, A., Sharpe, E., Andreescu, S., 2012. Nanoparticle-based technologies for the detection of food antioxidants. Curr. Anal. Chem. 8, 495-505. doi: $10.2174 / 157341112803216780$

Verma, M.S., Chen, P.Z., Jones, L., Gu, F.X., 2014. "Chemical nose" for the visual identification of emerging ocular pathogens using gold nanostars. Biosens. Bioelectron. 61, 386-390. doi:10.1016/j.bios.2014.05.045

Vladisavljević, G.T., Duncanson, W.J., Shum, H.C., Weitz, D.A., 2012. Emulsion templating of poly(lactic acid) particles: Droplet formation behavior. Langmuir 28, 12948-12954. doi:10.1021/la302092f

Vladisavljević, G.T., Laouini, A., Charcosset, C., Fessi, H., Bandulasena, H.C.H., Holdich, R.G., 2014. Production of liposomes using microengineered membrane and co-flow microfluidic device. Colloids Surfaces A Physicochem. Eng. Asp. 458, 168-177. doi:10.1016/j.colsurfa.2014.03.016

Wagner, J., Kirner, T., Mayer, G., Albert, J., Köhler, J., 2004. Generation of metal nanoparticles in a microchannel reactor. Chem. Eng. J. 101, 251-260. doi:10.1016/j.cej.2003.11.021

Wagner, J., Kohler, J.M., 2005. Continuous synthesis of gold nanoparticles in a microreactor. Nano Lett. 5, 685-691. doi:10.1021/n1050097t 
Zhao, S., Wang, W., Zhang, M., Shao, T., Jin, Y., Cheng, Y., 2012. Three-dimensional simulation of mixing performance inside droplets in micro-channels by Lattice Boltzmann method. Chem. Eng. J. 207-208, 267-277. doi:10.1016/j.cej.2012.06.098

Zhao, Y., Pang, B., Luehmann, H., Detering, L., Yang, X., Sultan, D., Harpstrite, S., Sharma, V., Cutler, C.S., Xia, Y., Liu, Y., 2016. Gold nanoparticles doped with 199 Au atoms and their use for targeted cancer imaging by SPECT. Adv. Healthc. Mater. 5, 928-935. doi:10.1002/adhm.201500992

Zheng, B., Ismagilov, R.F., 2005. A microfluidic approach for screening submicroliter volumes against multiple reagents by using preformed arrays of nanoliter plugs in a three-phase liquid/liquid/gas flow. Angew. Chem., Int. Ed. 44, 2520-2523. doi:10.1002/anie.200462857 